\title{
A novel acetone sensor utilizing cataluminescence on layered double oxide
}

\author{
Lijuan Zhang ${ }^{\mathrm{a}}$, Wanqi Rong ${ }^{\mathrm{a}}$, Yingchun Chen ${ }^{\mathrm{a}}$, Chao $\mathrm{Lu}^{\mathrm{a}, *}$, Lixia Zhao ${ }^{\mathrm{b}}$ \\ a State Key Laboratory of Chemical Resource Engineering, Beijing University of Chemical Technology, Beijing 100029, China \\ ${ }^{\mathrm{b}}$ State Key Laboratory of Environmental Chemistry and Ecotoxicology, Research Center for Eco-Environmental Sciences, Chinese Academy of Sciences, \\ Beijing 100085, China
}

\section{A R T I C L E I N F O}

\section{Article history:}

Received 16 June 2014

Received in revised form 18 August 2014

Accepted 21 August 2014

Available online 29 August 2014

\section{Keywords:}

Layered double oxide

Cataluminescence

Acetone

Sensor

\begin{abstract}
A B S T R A C T
This work developed a facile and effective sensor for the determination of acetone, the diabetic biomarker, which was based on cataluminescence (CTL) emission on the surface of layered double oxide (LDO) that is a layered nanomaterial with easy preparation and environmental friendliness. Under the optimized conditions, the linear range of the CTL intensity versus concentration of acetone was $0.1-16 \mathrm{mM}$ with the detection limit of $0.02 \mathrm{mM}(\mathrm{S} / \mathrm{N}=3)$. The relative standard deviation (RSD) for 50 repeated measurements of $1.0 \mathrm{mM}$ acetone was $3.6 \%$. Interestingly, there was no or weak response to seven common volatile organic compounds (VOCs), including ethanol, heptanal, ethyl acetate, methanol, formaldehyde, acetic acid and toluene. Furthermore, the proposed CTL sensor was successfully used for sensing acetone in human plasma samples of diabetes patients with a satisfactory recovery. The results demonstrated that the proposed CTL sensor had a promising capability for the sensing of acetone in diabetes diagnosis. The possible CTL mechanism from the oxidation of acetone on the surface of LDO was also discussed.
\end{abstract}

(C) 2014 Elsevier B.V. All rights reserved.

\section{Introduction}

Insulin is a naturally occurring hormone for metabolism and utilization of energy from the ingested nutrients (e.g., sugar and starches). The daily level of insulin is important for the body to function normally [1-3]. Diabetes patients are either unable to generate insulin or the insulin cannot work effectively [4]. Additionally, the medical reports show that a large amount of acetone is generated and acetone concentration is found to elevate by about two degrees of magnitude in the plasma of diabetic patients [5-7]. Hence, acetone is generally regarded as an important biomarker of diabetes or accessorial tool for diabetes diagnosis [8-16]. The commonly analytical techniques for determining acetone for diabetes diagnosis are based on derivatization techniques or mass spectrometry (MS) in conjunction with separation techniques, such as highperformance liquid chromatography (HPLC), gas chromatography (GC) [8-11]. However, the above-mentioned detection methods for acetone often suffer from some disadvantages, such as sophisticated procedures, bulky equipment and low detection sensitivity. In addition, the various types of acetone sensors based on different sensing principles have been fabricated due to their simplicity,

\footnotetext{
* Corresponding author. Tel.: +86 1064411957.

E-mail addresses: luchao@mail.buct.edu.cn, luchaohanghang@126.com (C. Lu).
}

precision and convenience. However, the reported acetone sensors are either poorly selective or inadequately sensitive [12-16].

Cataluminescence (CTL) is a kind of chemiluminescence (CL) during the catalytic oxidation of combustible gases on the surface of solid catalysts in an atmosphere containing oxygen $[17,18]$. In recent years, the applications of nanomaterial-based CTL to the construction of gas sensors for a variety of volatile organic compounds (VOCs) have attracted considerable attention owing to their advantages of stable intensity, low-cost devices, high sensitivity, and rapid response [19-23]. To the best of our knowledge, there is only one report on CTL determination for acetone in human plasma samples; however, it suffered low selectivity as it was also sensitive to other compounds besides acetone (e.g., methanol, ethanol and formaldehyde) [24]. To improve the selectivity toward acetone, ionic liquids-based headspace solid-phase microextraction technology was used to extract acetone before the CTL detection. Therefore, more efforts should be devoted to the development of a highly sensitive and selective acetone sensor-based CTL.

Layered double hydroxides (LDHs) are an interesting class of inorganic layered solid host matrices with structurally positively charged layers, interlayer balancing anionic species and water molecules [25]. Recently, calcination products of LDHs, known as layered double oxide (LDO), have been paid more attention as catalysts or catalyst precursors owing to their larger surface area, non-toxicity and high chemical stability [26-28]. It has been 
reported that LDO can exhibit stronger catalyzed activity toward aldol condensation of acetone that its LDH counterparts as a result of abundant basic sites [29-32]. Such improvements in catalytic properties are welcome to explore novel applications in sensors.

In the work, calcined $\mathrm{Mg} / \mathrm{Al}-\mathrm{CO}_{3} \mathrm{LDHs}(\mathrm{Mg} / \mathrm{Al}-\mathrm{LDO}$ ) were used as a novel sensing nanomaterial for preparing acetone sensor. Strong CTL emission was generated by the catalytic oxidation of acetone on the surface of LDO. The analytical characteristics were evaluated by the examination of CTL emission from trace acetone on the sensor. The proposed CTL sensor was highly sensitive and selective toward acetone with short response time and good stability. It enabled us to quantify the acetone levels without any sample pretreatments. Validation of the proposed method was checked by determining acetone in human plasma samples of diabetic patients. To the best of our knowledge, this is the first example to employ LDO as CTL sensing nanomaterial for the detection of acetone.

\section{Experimental}

\subsection{Reagents}

All reagents were of analytical grade and used without further purification. All solutions were prepared with deionized water (18.2 MU cm, Milli Q, Millipore, Barnstead, CA, USA). Analytical grade chemicals including $\mathrm{Mg}\left(\mathrm{NO}_{3}\right)_{2} \cdot 6 \mathrm{H}_{2} \mathrm{O}, \mathrm{Al}\left(\mathrm{NO}_{3}\right)_{3} \cdot 9 \mathrm{H}_{2} \mathrm{O}$, acetone, ethanol, ethyl acetate, methanol, formaldehyde, acetic acid, toluene, $\mathrm{Na}_{2} \mathrm{CO}_{3}$, and $\mathrm{NaOH}$ were purchased from Beijing Chemical Reagent Company (Beijing, China). Heptanal and 2,4-dinitrophenyl-hydrazine (DNPH) were purchased from Tokyo Chemical Industry Co., Ltd. HPLC grade acetonitrile was purchased from Merck KGaA (Darmstadt, Germany). CaO was purchased from Fuchen Chemical Reagent Company (Tianjin, China). Mesityl oxide and bromothymol blue (BTB, wt $0.04 \%$, water-soluble) were purchased from Tokyo Chemical Industry Co. Ltd. (Tokyo, Japan). A $200 \mathrm{mM}$ stock solution of acetone was freshly prepared by diluting $75 \mu \mathrm{L}$ of acetone into $5.0 \mathrm{~mL}$ of deionized water. A $0.17 \mathrm{~g} \mathrm{~mL}^{-1}$ $\mathrm{Ca}(\mathrm{OH})_{2}$ solution was freshly prepared by reaction of $\mathrm{CaO}$ with deionized water.

\subsection{Apparatus}

The powder X-ray diffraction (XRD) measurements were performed on Bruker (Germany) D8 ADVANCE X-ray diffractometer equipped with graphite-monochromatized $\mathrm{Cu} / \mathrm{K} \alpha$ radiation $(\lambda=1.5406 \AA$ ). The $2 \theta$ angle of the diffractometer was stepped from $5^{\circ}$ to $75^{\circ}$ at a scan rate of $10^{\circ} / \mathrm{s}$. The particle sizes and external morphology of the samples were observed on a transmission electron microscope (TEM, Tecnai G220, FEI Company). The CTL detection was conducted on an IFFM-E flow injection chemiluminescence analyzer (Ruimai, Xian, China). The CTL spectrum of this system was measured with high-energy cutoff filters from 400 to $640 \mathrm{~nm}$ between the CTL cell and the photomultiplier tube (PMT). The resultant gases produced by catalytic oxidation of acetone on the surface of LDO nanoparticles were collected in HPLC grade acetonitrile and then introduced into a Thermo Trace 1300-ISQ GC/MS system (Thermo, USA) equipped with a TR-5MS column ( $30 \mathrm{~m}, 0.25 \mathrm{~mm}$ i.d., and $0.25 \mu \mathrm{m}$ film thickness) for the analysis of the reaction products. Control experiments were performed using a Waters 1525 HPLC connected to an UV/visible detector (Waters 2489). A SunFire $C 18$ column $(4.6 \mathrm{~mm} \times 150 \mathrm{~mm}, 5.0 \mu \mathrm{m}$ particle size $)$ was used at room temperature. The LDO was calcined at $450^{\circ} \mathrm{C}$ in SX2-5-12 muffle (Boxun, Shanghai, China). Acetone was delivered by the air carrier gas (supplied by a pump, Beijing Zhongxing Huili Co. Ltd., Beijing, China). The heater controller (Hongbao Electric Co. Ltd., Beijing, China) was used to provide heat for the ceramic rod.

\subsection{Synthesis of $M g-A l L D O$}

The $\mathrm{Mg}-\mathrm{Al}-\mathrm{CO}_{3} \mathrm{LDHs}$ with different $\mathrm{Mg} / \mathrm{Al}$ molar ratios were prepared by the coprecipitation method. The precipitation process was taken under low supersaturation conditions at constant $\mathrm{pH}$ (10.0). Typically, for the synthesis of interlayer carbonate hydrotalcite sample with a $\mathrm{Mg} / \mathrm{Al}$ molar ratio of 3 , the salt solution including $\mathrm{Mg}\left(\mathrm{NO}_{3}\right)_{2} \cdot 6 \mathrm{H}_{2} \mathrm{O}(0.045 \mathrm{~mol})$ and $\mathrm{Al}\left(\mathrm{NO}_{3}\right)_{3} \cdot 9 \mathrm{H}_{2} \mathrm{O}(0.015 \mathrm{~mol})$ was made in $60 \mathrm{~mL}$ of deionized water. Then, the mixed solution $(60 \mathrm{~mL})$ containing $\mathrm{NaOH}(0.108 \mathrm{~mol})$ and $\mathrm{Na}_{2} \mathrm{CO}_{3}(0.0075 \mathrm{~mol})$ was prepared. The two solutions were added dropwise to a $250 \mathrm{~mL}$ fournecked flask under vigorous stirring at room temperature while the $\mathrm{pH}$ value kept 10.0 . The resulting white precipitate was continually stirred for $24 \mathrm{~h}$ at $60^{\circ} \mathrm{C}$. The products were centrifugated, washed with degassed and deionized water for three times, dried in vacuo at $65^{\circ} \mathrm{C}$ for $24 \mathrm{~h}$ and ground to a fine powder. The resulting solid powder was calcined at $450^{\circ} \mathrm{C}$ for $3 \mathrm{~h}$ before the CTL analysis.

\subsection{CTL measurements}

The CTL system was shown in Fig. S1. By diluting $200 \mathrm{mM}$ acetone stock solution with deionized water, a series of acetone working solutions were freshly obtained. A LDO suspension was prepared by diluting LDO powder in deionized water, then it was coated onto the cylindrical ceramic heater (inner diameter $=5 \mathrm{~mm}$, length $=8 \mathrm{~cm}$, Shanghai Anting Factory, Shanghai, China), which was then put into a quartz tube (diameter $=1 \mathrm{~cm}$, length $=10 \mathrm{~cm}$, Institute of Chemistry, Chinese Academy of Science, Beijing, China). A series of acetone solutions $(50 \mu \mathrm{L})$ were injected into a $2.0 \mathrm{~mL}$ gasification chamber, the gas would be conducted into a close reaction cell by air carrier gas. The CTL signals were monitored by a PMT adjacent to the CTL quartz tube. The data integration time of the CTL analyzer was set at $1 \mathrm{~s}$ per spectrum, and a work voltage of $900 \mathrm{~V}$ was used for the CTL detection. The signal was imported to the computer for data acquisition.

\subsection{Sample pretreatment}

Whole blood samples from diabetic patients were obtained from China-Japan Friendship Hospital, Beijing, China. The sealed centrifuge tube was used to collect blood samples by a heparincontaining syringe. To minimize the loss of acetone, whole blood samples were stored at $-20^{\circ} \mathrm{C}$ and thawed at $4{ }^{\circ} \mathrm{C}$ just before analysis. After the plasma samples were obtained via centrifugation at $5000 \mathrm{rpm}$ for $5 \mathrm{~min}$, it was analyzed immediately by the proposed CTL sensor.

\section{Results and discussion}

\subsection{LDO-triggered acetone $C T L$}

The TEM image and the representative XRD pattern of LDO with the $\mathrm{Mg} / \mathrm{Al}$ ratio of 4 indicated that the LDH layer collapsed into small pieces with a higher crystallinity after calcination. Additionally, to obtain the CTL response profile of acetone on the surface of LDO, different concentrations of acetone were injected into the air carrier with a flow rate of $400 \mathrm{~mL} \mathrm{~min}^{-1}$ at $300^{\circ} \mathrm{C}$ working temperature. The curves 1,2 and 3 of Fig. 1 denoted the results for different acetone concentrations of $10 \mathrm{mM}, 20 \mathrm{mM}$ and $30 \mathrm{mM}$, respectively. We could observe that the CTL signals increased with an increase in the concentration of acetone. For the three concentrations of acetone, the signals rapidly increased from the baseline to the maximum value within around $3 \mathrm{~s}$ after sample injection, indicating that the proposed sensing mode exhibited a rapid response to different concentrations of acetone. 


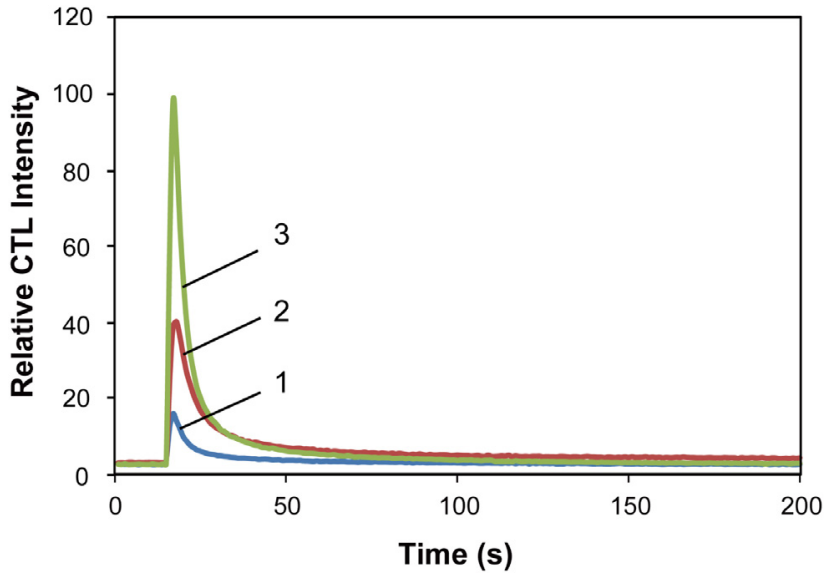

Fig. 1. CTL response profiles of different concentrations of acetone. Conditions: acetone concentration, $10 \mathrm{mM}, 20 \mathrm{mM}$ and $30 \mathrm{mM}$, respectively; reaction temperature,

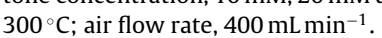

\section{2. $\mathrm{Mg}$ to Al molar ratios}

It has been reported that the $\mathrm{Mg} / \mathrm{Al}$ ratio of $\mathrm{LDO}$ has a great effect on its catalytic performances [33]. Note that the large values of $\mathrm{Mg} / \mathrm{Al}$ ratio (e.g., $\mathrm{Mg} / \mathrm{Al}$ molar ratio $=5,6$ ) can lead to a high density of Mg octahedra in the LDH sheet, facilitating the formation of $\mathrm{Mg}(\mathrm{OH})_{2}$ or $\mathrm{MgCO}_{3}$ [34]. In this study, the effect of LDO with $\mathrm{Mg} / \mathrm{Al}$ molar ratios varying from 2 and 4 on the CTL intensity was investigated. The results showed that the CTL intensity of LDO with the $\mathrm{Mg} / \mathrm{Al}$ molar ratio of 4 was strongest. This might due to the increasing basic sites of $\mathrm{LDO}$ when the $\mathrm{Mg} / \mathrm{Al}$ ratio was from 2 to 4 , facilitating the proceeding of the CTL reaction [29]. Therefore, the $\mathrm{LDO}$ with the $\mathrm{Mg} / \mathrm{Al}$ molar ratio of 4 was used throughout this study.

\subsection{CTL reaction temperature}

The working temperature for CTL reaction was still an important factor in the reaction rate of the catalytic oxidation reaction. The CTL intensity for acetone improved with the increased temperature owing to the higher conversion of acetone on LDO at higher temperature [35]. However, higher temperature (above $300^{\circ} \mathrm{C}$ ) could result in partly desorption of LDO on the ceramic rod. Therefore, $300{ }^{\circ} \mathrm{C}$ was selected as the optimal temperature in this work.

\subsection{Flow rate of carrier gas}

The acetone vapor and the selected catalyst would have a proper contact time with a proper flow rate [21]. Therefore, the effect of carrier gas flow rate on the CTL intensity was examined in the range of $150-750 \mathrm{~mL} \mathrm{~min}^{-1}$ (Fig. 2). The CTL intensity of acetone increased gradually with increasing the air flow rate in the range of 150-400 $\mathrm{mL} \mathrm{min}^{-1}$. However, when the flow rate was higher than $400 \mathrm{~mL} \mathrm{~min}^{-1}$, the CTL intensity decreased due to the fact that the reaction time between acetone and catalyst would possibly not be sufficient. Therefore, $400 \mathrm{~mL} \mathrm{~min}^{-1}$ was chosen as the optimal flow rate for the subsequent studies.

\subsection{Highly selectivity toward acetone}

The selectivity of CTL sensors is important for their real analytical applications. In this proposed system, we interestingly found that LDO nanoparticles showed an excellent selectivity toward acetone by testing the other seven kinds of common VOCs under the same experimental conditions with the concentration

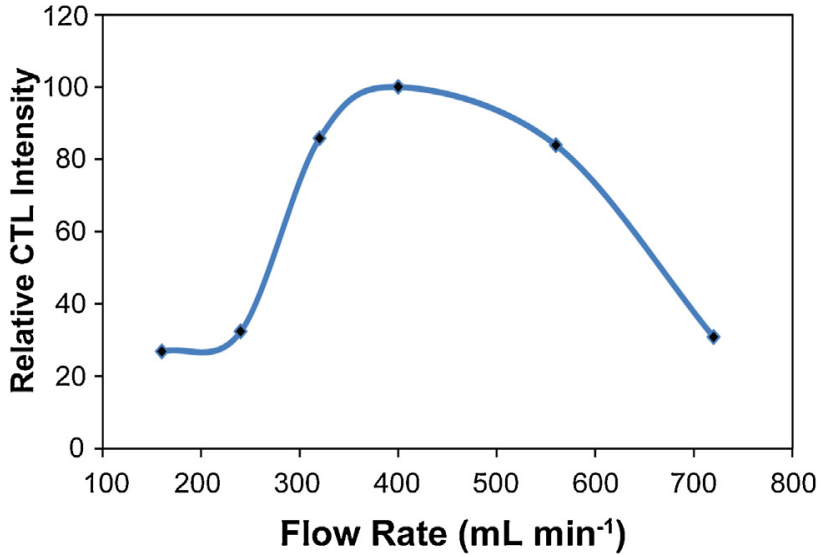

Fig. 2. Effect of flow rate of carrier gas on the CTL intensity. Conditions: acetone concentration, $10 \mathrm{mM}$; reaction temperature, $300^{\circ} \mathrm{C}$.

of $1.0 \mathrm{mM}$. These VOC species included ethanol, heptanal, ethyl acetate, methanol, formaldehyde, acetic acid and toluene. As shown in Fig. 3, the above-mentioned seven common VOCs exhibited no or very weak CTL signals, indicating that the present gas sensor may be used to sense acetone with high selectivity. There are some causes to contribute to high selectivity toward acetone: (1) the medium-strength basic sites of LDO nanoparticles could exhibit its highly catalytic performances in the conversion of acetone into CTL emitting species because the aldol condensation of acetone occurs mainly on basic sites [29,31]; (2) in comparison to the other compounds tested, the carbon-oxygen double bond in acetone is easily cleaved, facilitating the proceeding of aldol condensation; and (3) the aldol condensation of acetone could easily take place in lower operation temperatures, but the other compounds tested in aldol condensation reactions own slow reaction rate in lower temperatures [32]. In addition, note that the concentration of acetone in diabetes patients is much higher than those of the other compounds tested $[10,24]$. Therefore, the CTL on the surface of LDO nanoparticles exhibited highly selective recognition toward acetone under the optimal conditions.

\subsection{Analytical characteristics}

Under the optimum experimental conditions, the CTL intensity was increased with an increase in the concentration of acetone (e.g., $500 \mathrm{mM}$ ). However, the CTL intensity was proportional to the concentration of acetone in the range from 0.1 to $16 \mathrm{mM}$. The regression

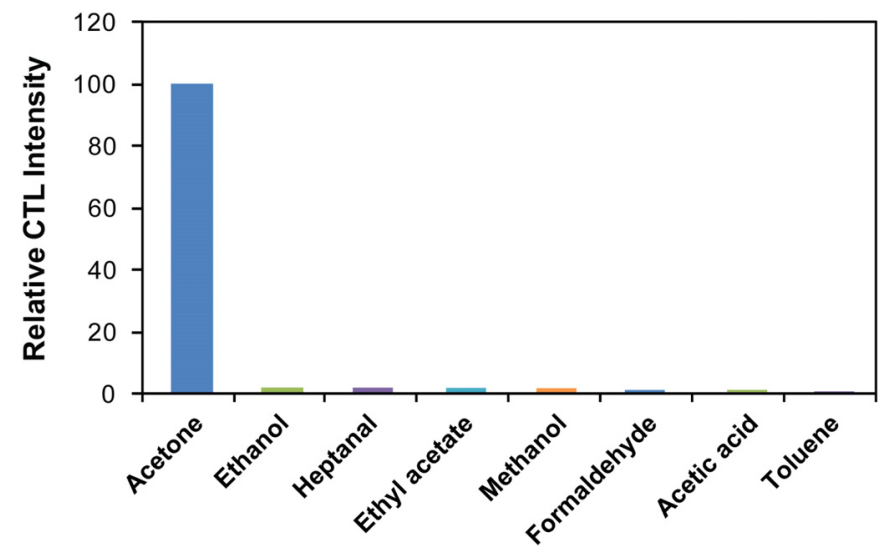

Fig. 3. Selectivity of CTL sensor toward acetone based on LDO nanoparticles. Conditions: VOC concentration, $1.0 \mathrm{mM}$; reaction temperature, $300^{\circ} \mathrm{C}$; air flow rate, $400 \mathrm{~mL} \mathrm{~min}^{-1}$. 

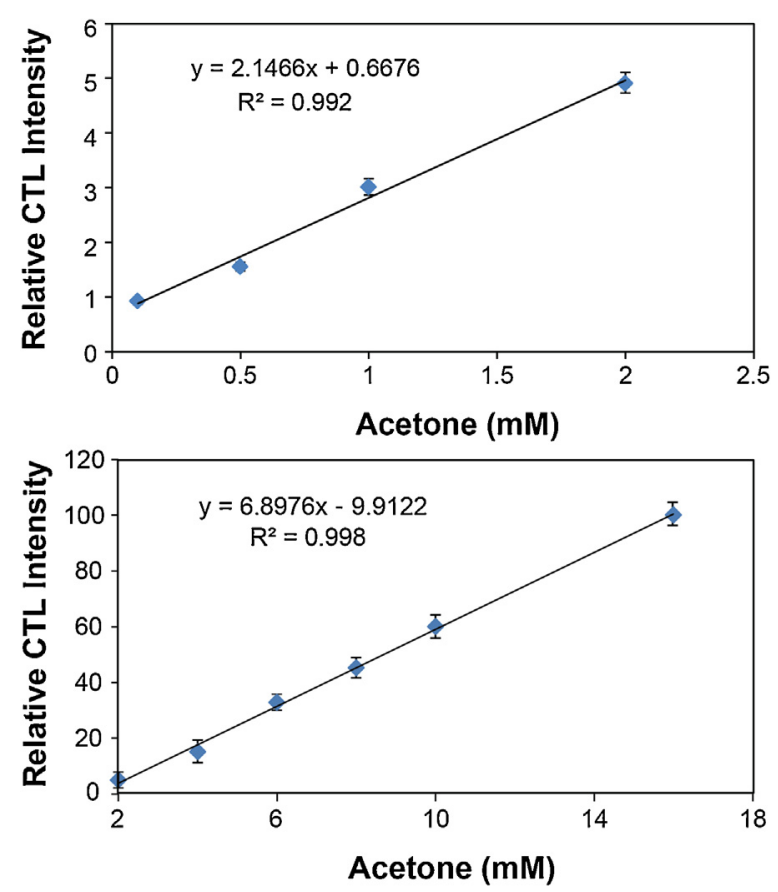

Fig. 4. Two linear regions between CTL intensity and acetone concentration. Conditions: reaction temperature, $300{ }^{\circ} \mathrm{C}$; air flow rate, $400 \mathrm{~mL} \mathrm{~min}^{-1}$.

equation was $\Delta I=6.3878 C-4.5723\left(R^{2}=0.991\right)$, where $\Delta I$ was the relative CTL intensity and $C$ was the concentration of acetone, respectively (Fig. 4). The detection limit for acetone $(\mathrm{S} / \mathrm{N}=3)$ was $0.02 \mathrm{mM}$, and the CTL response profile of acetone at the limit of detection was shown in Fig. S2. In addition, the stability of the proposed CTL sensor was carried out by continually injecting $50 \mu \mathrm{L}$ of $1.0 \mathrm{mM}$ acetone into the sensor chamber for 50 times under the optimum conditions, the relative standard deviation (RSD) was $3.6 \%$, indicating an acceptable stability. After several months, the CTL intensity was approximately $96 \%$ of its initial value. Therefore, the present sensor showed a good long-term reproducibility.

\subsection{Real samples}

It is reported that acetone level in plasma of normal donors is below $0.008 \mathrm{mM}$, which is lower than the $0.02 \mathrm{mM}$ detection limit in the proposed method [9]. In order to evaluate the applicability and reliability of the proposed method, it was applied for the determination of acetone in human plasma samples of diabetes patients. The pretreated plasma samples were analyzed immediately. Acetone in human plasma samples was well quantified using a standard addition method, and the results were shown in Table 1, which were in good agreement with those obtained by the accepted HPLC-UV detection method for acetone [24]. To evaluate the accuracy of this method, the recovery of known amounts of acetone added to the human plasma samples were tested. The good recoveries of acetone obtained ranged from $97 \%$ to $104 \%$, indicating the good accuracy of the proposed method. These satisfactory results demonstrated the reliability of the present method for detecting acetone in real samples.

\subsection{Possible mechanism of the CTL reaction}

To study the CTL mechanism of the acetone sensor, GC/MS was carried out to detect the reaction products of the catalytic oxidation of acetone on the surface of LDO nanoparticles. Acetonitrile was used to collect the tail gases. GC/MS data demonstrated the production of the traces of mesityl oxide during the CTL reaction (Fig. 5a), and there were no other products detected. These results were in agreement with our previous work [29]. In addition, we found that the CTL intensity of $1.0 \mathrm{mM}$ mesityl oxide was the same as that of $2.0 \mathrm{mM}$ acetone, which may be attributed to the fact that the aldol condensation of two acetone molecules can generate one molecule mesityl oxide [32]. The CTL spectrum of the present CTL system was measured using a series of high-energy cutoff filters from 400 to $640 \mathrm{~nm}$. It could be clearly seen from Fig. $5 \mathrm{~b}$ that the maximum emission wavelength for the present CTL system was about $550 \mathrm{~nm}$, meaning that the emissive species for the observed CTL was carbon dioxide molecules in the electronic excited state $\left(\mathrm{CO}_{2}{ }^{*}\right)$ rather than the excited state of mesityl oxide. Next, $\mathrm{CO}_{2}{ }^{*}$ could produce photoemissions when returning to its ground states [36]. On the other

Table 1

Assay results of acetone in human plasma samples.

\begin{tabular}{|c|c|c|c|c|c|}
\hline Samples & CTL method $^{\mathrm{a}}(\mathrm{mM})$ & HPLC-UV method $^{\mathrm{a}}(\mathrm{mM})$ & Added (mM) & Found $^{\mathrm{a}}(\mathrm{mM})$ & Recovery (\%) \\
\hline Plasma 1 & $1.32 \pm 0.07$ & $1.21 \pm 0.09$ & $\begin{array}{l}1.00 \\
2.00\end{array}$ & $\begin{array}{l}2.30 \pm 0.05 \\
3.21 \pm 0.08\end{array}$ & $\begin{array}{r}104 \\
97\end{array}$ \\
\hline Plasma 2 & $0.91 \pm 0.04$ & $0.97 \pm 0.03$ & $\begin{array}{l}1.00 \\
2.00\end{array}$ & $\begin{array}{l}1.96 \pm 0.09 \\
2.97 \pm 0.03\end{array}$ & $\begin{array}{l}103 \\
102\end{array}$ \\
\hline
\end{tabular}

a Mean \pm SD of three measurements.
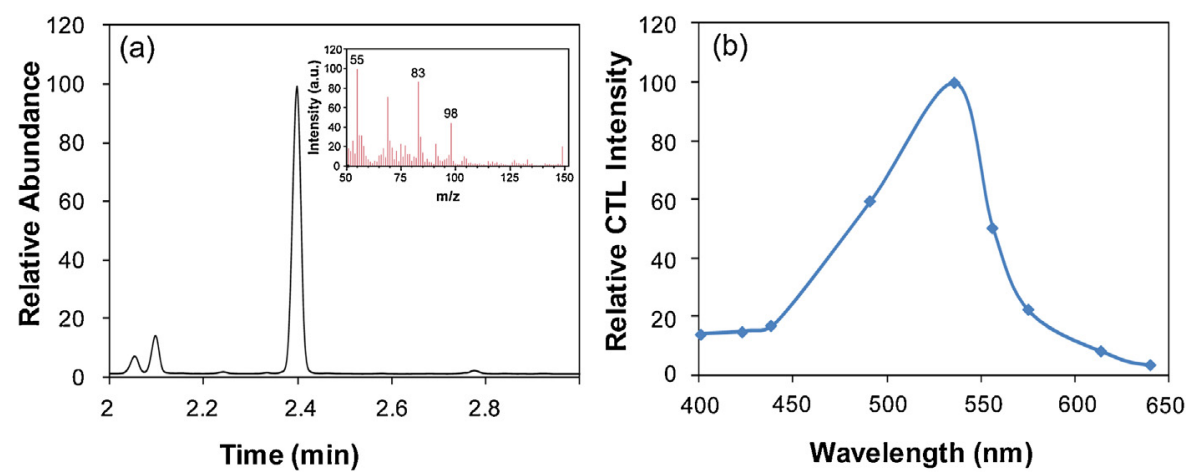

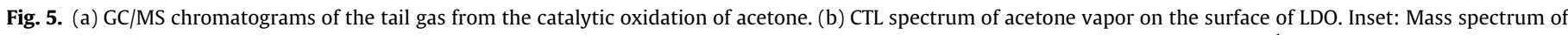
the GC peak at $2.4 \mathrm{~min}$ (mesityl oxide). Conditions: acetone concentration, $10 \mathrm{mM}$; reaction temperature, $300^{\circ} \mathrm{C}$; air flow rate, $400 \mathrm{~mL} \mathrm{~min}^{-1}$. 
hand, the final oxidation products of acetone were confirmed by using BTB ( $\mathrm{pH}$ indicator) and $\mathrm{Ca}(\mathrm{OH})_{2}$ solutions. As shown in Fig. $\mathrm{S} 3$, an obvious color change from blue (at $\mathrm{pH} \geq 8$ ) to green (at $\mathrm{pH}$ $6-7$ ) of $0.01 \mathrm{wt} \%$ BTB aqueous solution could be seen when the tail gases were injected, indicating the generation of $\mathrm{CO}_{2}$. After the acetone oxidation products were captured in $\mathrm{Ca}(\mathrm{OH})_{2}$ solution, it was found that the clear solution turned to turbid. These results were in agreement with our previous work [29]. Based on the above results, the possible mechanism of the acetone CTL was as follows. When acetone vapor passed through the surface of the ceramic heaters, the aldol condensation of acetone happened in the presence of $\mathrm{O}_{2}$. The produced mesityl oxide could easily further be oxidized to $\mathrm{CO}_{2}$ * in the presence of $\mathrm{LDO}$ nanoparticles. Finally, $\mathrm{CO}_{2}$ in the electronic excited state could produce photoemission when it returned to its ground states.

\section{Conclusions}

In summary, LDO nanoparticles are easily prepared and environmentally friendly. For the first time, we have demonstrated the feasibility to design a CTL sensor for the quantitative analysis of acetone by using LDO nanoparticles as catalysts. The proposed acetone CTL sensor exhibited highly selective and sensitive recognition toward acetone with satisfactory stability and simplicity. Combined with its simple apparatus and its long-term stability, the implementation of the proposed sensor has been applied for the sensing of acetone in human plasma samples of diabetes patients. The development of sensor arrays for gas mixture recognition should be explored through tuning different kinds of LDO.

\section{Acknowledgments}

This work was supported by the National Natural Science Foundation of China (21375006 and 21177138), the 973 Program (2011CBA00503), and the Fundamental Research Funds for the Central Universities (JD1311). We also thank Prof. Xue Duan, Beijing University of Chemical Technology for his valuable discussions.

\section{Appendix A. Supplementary data}

Supplementary data associated with this article can be found, in the online version, at http://dx.doi.org/10.1016/j.snb.2014.08.064.

\section{References}

[1] N. Cheung, P. Mitchell, T.Y. Wong, Diabetic retinopathy, Lancet 376 (2010) $124-136$

[2] M. Kitada, Z.Y. Zhang, A. Mima, G.L. King, Molecular mechanisms of diabetic vascular complications, J. Diabetes Investig. 1 (2010) 77-89.

[3] M. Brownlee, Biochemistry and molecular cell biology of diabetic complications, Nature 414 (2001) 813-820.

[4] R.J. McCrimmon, C.M. Ryan, B.M. Frier, Diabetes and cognitive dysfunction, Lancet 379 (2012) 2291-2299.

[5] M.P. Kalapos, On the mammalian acetone metabolism: from chemistry to clinical implications, Biochim. Biophys. Acta 1621 (2003) 122-139.

[6] M.W. Savage, K.K. Dhatariya, A. Kilvert, G. Rayman, J.A.E. Rees, C.H. Courtney, L. Hilton, P.H. Dyer, M.S. Hamersley, Joint British Diabetes Societies guideline for the management of diabetic ketoacidosis, Diabet. Med. 28 (2011) 508-515.

[7] M. Veciana, Diabetes ketoacidosis in pregnancy, Semin. Perinatol. 37 (2013) 267-273.

[8] S. Fujii, T. Maeda, I. Noge, Y. Kitagawa, K. Todoroki, K. Inoue, J.Z. Min, T. Toyo'oka, Determination of acetone in saliva by reversed-phase liquid chromatography with fluorescence detection and the monitoring of diabetes mellitus patients with ketoacidosis, Clin. Chim. Acta 430 (2014) 140-144.

[9] L. Dong, X.Z. Shen, C.H. Deng, Development of gas chromatography-mass spectrometry following headspace single-drop microextraction and simultaneous derivatization for fast determination of the diabetes biomarker, acetone in human blood samples, Anal. Chim. Acta 569 (2006) 91-96.

[10] N. Li, C.H. Deng, N. Yao, X.Z. Shen, X.M. Zhang, Determination of acetone, hexanal and heptanal in blood samples by derivatization with pentafluorobenzyl hydroxylamine followed by headspace single-drop microextraction and gas chromatography-mass spectrometry, Anal. Chim. Acta 540 (2005) 317-323.
[11] G.-T. Fan, C.-L. Yang, C.-H. Lin, C.-C. Chen, C.-H. Shih, Applications of Hadamard transform-gas chromatography/mass spectrometry to the detection of acetone in healthy human and diabetes mellitus patient breath, Talanta 120 (2014) 386-390.

[12] S.-J. Choi, I. Lee, B.-H. Jang, D.-Y. Youn, W.-H. Ryu, C.O. Park, I.-D. Kim, Selective diagnosis of diabetes using Pt-functionalized $\mathrm{WO}_{3}$ hemitube networks as a sensing layer of acetone in exhaled breath, Anal. Chem. 85 (2013) 1792-1796.

[13] P. Sun, Y.X. Cai, S.S. Du, X.M. Xu, L. You, J. Ma, F.M. Liu, X.S. Liang, Y.F. Sun G.Y. Lu, Hierarchical $\alpha-\mathrm{Fe}_{2} \mathrm{O}_{3} / \mathrm{SnO}_{2}$ semiconductor composites: hydrotherma synthesis and gas sensing properties, Sens. Actuators B: Chem. 182 (2013) 336-343.

[14] M. Righettoni, A. Tricoli, S.E. Pratsinis, $\mathrm{Si}: \mathrm{WO}_{3}$ sensors for highly selective detection of acetone for easy diagnosis of diabetes by breath analysis, Anal. Chem. 82 (2010) 3581-3587.

[15] T.I. Nasution, I. Nainggolan, S.D. Hutagalung, K.R. Ahmad, Z.A. Ahmad, The sensing mechanism and detection of low concentration acetone using chitosanbased sensors, Sens. Actuators B: Chem. 177 (2013) 522-528.

[16] T. Xiao, X.-Y. Wang, Z.-H. Zhao, L. Li, L. Zhang, H.-C. Yao, J.-S. Wang, Z.-J. Li, Highly sensitive and selective acetone sensor based on C-doped $\mathrm{WO}_{3}$ for potential diagnosis of diabetes mellitus, Sens. Actuators B: Chem. 199 (2014) 210-219.

[17] R.A. Potyrailo, V.M. Mirsky, Combinatorial and high-throughput development of sensing materials: the first 10 years, Chem. Rev. 108 (2008) 770-813.

[18] N. Na, S.C. Zhang, X. Wang, X.R. Zhang, Cataluminescence-based array imaging for high-throughput screening of heterogeneous catalysts, Anal. Chem. 81 (2009) 2092-2097.

[19] R.K. Zhang, X.A. Cao, Y.H. Liu, X.Y. Chang, Development of a simple cataluminescence sensor system for detecting and discriminating volatile organic compounds at different concentrations, Anal. Chem. 85 (2013) 3802-3806.

[20] M.R. Almasian, N. Na, F. Wen, S.C. Zhang, X.R. Zhang, Development of a plasmaassisted cataluminescence system for benzene, toluene, ethylbenzene, and xylenes analysis, Anal. Chem. 82 (2010) 3457-3459.

[21] L. Tang, Y. Li, K.L. Xu, X.D. Hou, Y. Lv, Sensitive and selective acetone senso based on its cataluminescence from nano- $\mathrm{La}_{2} \mathrm{O}_{3}$ surface, Sens. Actuators B: Chem. 132 (2008) 243-249.

[22] W. Sha, D.F. Cui, B. Li, Q.H. Wang, Y.H. Wang, C.H. Zheng, A portable embedded drug precursor gas detection and identification device based on cataluminescence-based sensor array, Sens. Actuators B: Chem. 200 (2014) $132-139$.

[23] X.Y. Wan, H.J. Song, D. Zhao, L.C. Zhang, Y. Lv, A Y-doped metal-organic framework-based cataluminescence gas sensor for isobutanol, Sens. Actuators B: Chem. 201 (2014) 413-419.

[24] P. Yang, C. Lau, X. Liu, J.Z. Lu, Direct solid-support sample loading for fast cataluminescence determination of acetone in human plasma, Anal. Chem. 79 (2007) 8476-8485.

[25] Q. Wang, D. O'Hare, Recent advances in the synthesis and application of layered double hydroxide (LDH) nanosheets, Chem. Rev. 112 (2012) 4124-4155.

[26] M.-Y. Guan, D.-M. Xu, Y.-F. Song, Y. Guo, $\mathrm{ZnO} / \mathrm{ZnAl}_{2} \mathrm{O}_{4}$ prepared by calcination of $\mathrm{ZnAl}$ layered double hydroxides for ethanol sensing, Sens. Actuators B: Chem. 188 (2013) 1148-1154.

[27] L. Cui, H.S. Yin, J. Dong, H. Fan, T. Liu, P. Ju, S.Y. Ai, A mimic peroxidase biosensor based on calcined layered double hydroxide for detection of $\mathrm{H}_{2} \mathrm{O}_{2}$, Biosens. Bioelectron. 26 (2011) 3278-3283.

[28] Y.J. Lin, Q.L. Fang, B.L. Chen, Perchlorate uptake and molecular mechanisms by magnesium/aluminum carbonate layered double hydroxides and the calcined layered double hydroxides, Chem. Eng. J. 237 (2014) 38-46.

[29] L.J. Zhang, Y.C. Chen, N. He, C. Lu, Acetone cataluminescence as an indicator for evaluation of heterogeneous base catalysts in biodiesel production, Anal. Chem. 86 (2014) 870-875.

[30] L. Faba, E. Díaz, S. Ordóñez, Aqueous-phase furfural-acetone aldol condensation over basic mixed oxides, Appl. Catal. B 113-114 (2012) 201-211.

[31] P. Kuśtrowski, D. Sułkowska, L. Chmielarz, A. Rafalska-Łasocha, B. Dudek R. Dziembaj, Influence of thermal treatment conditions on the activity of hydrotalcite-derived $\mathrm{Mg}$-Al oxides in the aldol condensation of acetone, Microporous Mesoporous Mater. 78 (2005) 11-22.

[32] S. Ordóñez, E. Díaz, M. León, L. Faba, Hydrotalcite-derived mixed oxides as catalysts for different $\mathrm{C}-\mathrm{C}$ bond formation reactions from bioorganic materials, Catal. Today 167 (2011) 71-76.

[33] D. Tichit, M. Naciri Bennani, F. Figueras, R. Tessier, J. Kervennal, Aldol condensation of acetone over layered double hydroxides of the meixnerite type, Appl. Clay Sci. 13 (1998) 401-415.

[34] H. Yan, M. Wei, J. Ma, D.G. Evans, X. Duan, Plane-wave density functional theory study on the structural and energetic properties of cation-disordered $\mathrm{Mg}-\mathrm{Al}$ layered double hydroxides, J. Phys. Chem. A 114 (2010) 7369-7376.

[35] J. Hu, K.L. Xu, Y.Z. Jia, Y. Lv, Y.B. Li, X.D. Hou, Oxidation of ethyl ether on borate glass: chemiluminescence, mechanism, and development of a sensitive gas sensor, Anal. Chem. 80 (2008) 7964-7969.

[36] R.K. Zhang, X.A. Cao, Y.H. Liu, X.Y. Chang, A new method for identifying compounds by luminescent response profiles on a cataluminescence based sensor, Anal. Chem. 83 (2011) 8975-8983.

\section{Biographies}

Lijuan Zhang received her Ph.D. degree in Materials Science from Beijing University of Chemical Technology. She is currently an associate professor of State 
Key Laboratory of Chemical Resource Engineering, Beijing University of Chemical Technology. Her areas of interests include nanoscale material sensors and electroanalytical chemistry.

Wanqi Rong is currently a master student at Beijing University of Chemical Technology, Beijing, China. She is engaged in the preparation, characterization of nanoparticles, and potential application as cataluminescence sensors.

Yingchun Chen received her master degree from Beijing University of Chemical Technology of analytical chemistry. Her current research topic is nanoparticlecatalyzed cataluminescence.

Chao Lu received his Ph.D. degree in Materials Science from Chinese Academy of Sciences. He is currently a full professor of State Key Laboratory of Chemical Resource
Engineering, Beijing University of Chemical Technology. In 2011, he was selected to participate in the 'New Century Outstanding Talent' scheme of the Ministry of Education. His research interests are focused on the synthesis, characterization of nanostructured materials, nanosensors, cataluminescence, and chemiluminescence. He is responsible of national and international research projects and has published more than 70 papers in peer-refereeing international journals.

Lixia Zhao received her Ph.D. degree in Environmental Science from Chinese Academy of Sciences. She is currently an associate professor of Research Center for Eco-Environmental Science, CAS. Her research interests are focused on the nanoparticle chemiluminescence, chemiluminescence immunoassay and its application in environmental monitoring. She is responsible of national research projects and has published more than 30 papers in peer-refereeing international journals. 